\title{
Research on Cigarettes Customer Needs Importance Algorithm Based on KJ / RAHP / KANO
}

\author{
Xiong-Jun NI ${ }^{1}$, Pei HE ${ }^{1}$, Wen-Xi XU ${ }^{1}$, Yue-Xiong GONG ${ }^{1}$, Qiang ZHU1 ${ }^{1}$, Wei-Zhong HUANG ${ }^{1}$, Juan-Li WANG ${ }^{2}$ \\ ${ }^{a}$ China Tobacco Zhejiang Industrial Company Limited, Hangzhou, 310024, China. \\ ${ }^{\mathrm{b}}$ Zhejiang University of Water Resources and Electric Power, Hangzhou, 310018, China \\ gongyuexiong@zjtobacco.com
}

\begin{abstract}
To express the ambiguity and uncertainty of customer needs importance, an algorithm was proposed. It integrated KJ method, rough analytic Hierarchy Process and KANO model. It calculated the customer needs importance in rough set. A case study of cigarettes customer needs importance illustrated the feasibility and validity of the algorithm.
\end{abstract}

\section{Research Background and Significance}

Customer needs importance information is an important input of QFD (Quality Function Deployment). Most existing researches on customer needs importance algorithm based on QFD focuses on combining fuzzy set and AHP to calculate customer needs importance. Although fuzzy set can solve uncertainty and ambiguity of customer needs information, customer needs algorithm based on fuzzy sets is subjective because fuzzy set needs pre-set membership function of fuzzy numbers. However, rough set needs not any pre-set parameters, the data can "speak by themselves", which has more advantages in solving uncertainty and ambiguity of customer needs information compared with fuzzy sets. In addition, although AHP (Analytic Hierarchy Process) has advantages in calculating relative importance of customer needs sub-items under the same parent item, but there may be a relatively large difference in the number of customer needs sub-items under different parent items, which will, to some extent, affect AHP effectiveness. As for solving relative importance of customer needs sub-items which are at the same level but belong to different parent items, KANO model has a comparative advantage. Therefore, it is necessary to use KANO model to further adjust customer needs information processed by AHP, QFD provides the possibility of integration between KANO model and AHP.

\section{Customer Needs Analysis framework Based on KJ / RAHP / KANO}

The framework of customer needs analysis based on $\mathrm{KJ} /$ RAHP / KANO is in Figure 1.

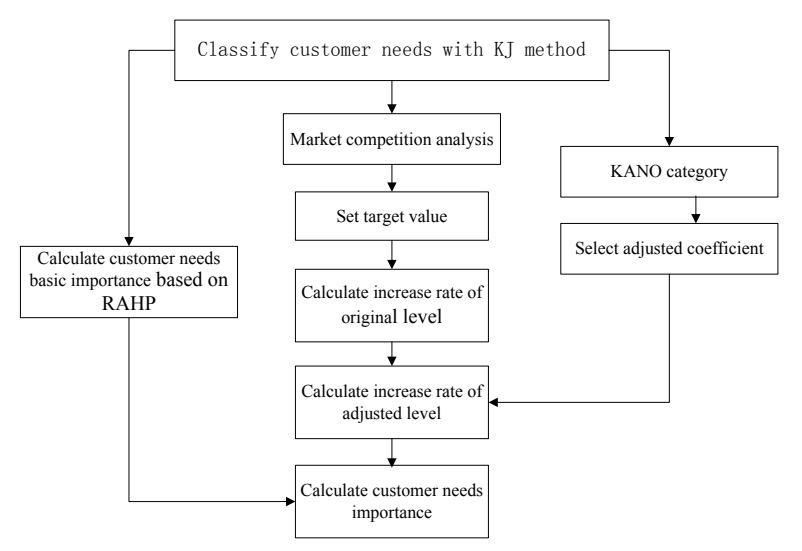

Fig. 1 Customer needs analysis framework based on KJ / RAHP / KANO

Source: This study.

\section{Calculate customer needs with $\mathrm{KJ}$ method}

Customer needs information obtained through market research is quite complex, and the same meaning may be expressed in many different ways; some customer needs information are broad, while some are very narrow; some customer needs information contains other customer needs information. Therefore, it is necessary to classify and simplify customer needs information by using Affinity Diagram, KJ method to give an analysis of customer needs information. KJ method will be used to clarify the customer needs in this paper.

\section{Determination method of customer needs importance based on RAHP}

Customer needs information with hierarchical structure can be clarified with $\mathrm{KJ}$ method, indicating subordination and containing the relationship between customer needs concept, which plays an important role in expressing and understanding complex customer needs information (Cheng, 
Y., Leu, S., 2011). Due to the complexity of customer needs information and limitation of KJ legal analysis method, customer needs information which is got from KJ method cannot express relative importance between customer needs, and there are still multi-meanings, uncertainty and ambiguity. So it needs to further tap customer needs information and solve its multi-meanings, uncertainty and ambiguity by combining quantitative analysis method. Customer needs importance determining method based on RAHP (Rough Analytic Hierarchy Process) provides an effective solution to expressing relative importance of customer needs and solving multi-meaning, uncertainty and ambiguity of customer needs information.

\section{RAHP-related concepts and definitions}

AHP method can completely reflect the system analysis of system engineering and system integration idea. It takes a complex problem as a system, and in system analysis phase, according to membership function between factors within the system, transforms a complex problem into a methodical and hierarchal problem, and directly reflects the relationship between factors within the system in the form of hierarchical diagram. This decomposes complex system into relatively simple subsystems, and then integrates them step by step (in system integration phase).

\section{Calculation steps of customer needs importance based on RAHP}

AHP is easy to operate, especially for more complex customer needs analysis, but AHP itself is unable to cope with ambiguity and subjectivity of customer language, and is also unable to cope with judgment from many decision-makers. Application of rough number and rough boundary interval on AHP analysis can enable customer needs analysis to better cope with ambiguity of information evaluation from customer, while gathering judgment information from several survey participants, making judgment of customer needs importance more representative. Existing rough sets and research combining with AHP mostly discusses how to reduce evaluation guidelines by rough sets, namely, reducing the number of items in sub-hierarchy (Jain, VK, Sobek, DK, 2006; Zongjun Wang, Maoguang Chu, 2009). Customer needs determining method based on rough AHP proposed by Xiaotun Wang (2010) provides the idea of calculating customer needs importance with rough number and rough interval. But with this calculation method, customer needs importance expressed with rough number is transformed into the numerical form in the fifth step, to some extent; it weakens the advantage of rough number uncertainty and ambiguity (Xiaotun Wang, 2010). In this paper, customer needs importance determining method based on rough AHP proposed by Xiaotun Wang (2010) was amended, proposing that customer needs importance is always be expressed in the form of rough number.

\section{KANO model and customer needs weight adjustment method}

The concept of multidimensional quality property

According to Kano (2001), quality property can change over time, that is to say, a successful property will follow the life cycle of from indifference to an attractive, to become one-dimensional single item, and eventually become a must. For example, a property may be indifferent by customers when it first enters the market. But with the development of market, the property may become attractive, that is to say, it makes customers feel satisfied, even if the product does not contain the property, customers will think it is normal. However, if the property disappears, customers who frequently use this property will feel quite dissatisfied. After frequent use, the perception of this property might become one-dimensional and customers will satisfy or dissatisfy it depending on the satisfaction extent of this property. As time passes, one-dimensional property value will be accepted by consumers, and gradually become an item taken for granted (Kano, 2001).

\section{KANO classification and customer need weighting correction coefficient}

Relationship of customer satisfaction existing in KANO model and product (service) performance can be expressed approximately with a function $s=f(k, p), \quad s$ means customer satisfaction, $p$ is product (service) performance, $k$ is adjustment coefficient of KANO classification.

Obviously, a good product (service) performance can bring high customer satisfaction, and the information brought by KANO model is much more. KANO model tells us that contribution of each customer satisfaction property to customer satisfaction is not equal. Not only each customer satisfaction property is different in customer satisfaction importance, but also contribution way of each customer satisfaction property to total customer satisfaction is different (Kano, 1984).

In order to obtain maximum customer satisfaction with the most economical cost, QFD practitioners not only need to be clear what customers need most, but also need to know the cost of each customer need to obtain desired customer satisfaction level. KANO adjustment coefficient and conversion function provides useful information.

Customer need classification information based on KANO model through market competition analysis combines with customer need basic importance algorithm based on amended RAHP constitutes customer need importance algorithm based on RAHP and KANO models.

\section{Case study on Cigarette Customer Needs}

To illustrate the feasibility and effectiveness of customer needs importance algorithm based on KANO and RAHP models, I selected cigarettes as an example, to explain customer needs importance algorithm and verify its effectiveness based on RAHP and KANO models. 


\section{Cigarette customer needs analysis}

When customers express their needs information in the voice of customer (VOC), the form is usually various, including comments, complaints, evaluation, and hope, so original data collected not only has complex content but also has mixed concepts. KJ method is used to clarify and reduce customer needs information. KJ method to process cigarette customer needs, which are good taste, strong taste, no throat hurting, steady quality, and good package.

\section{Cigarette customer needs importance determining method based on RAHP}

(1) AHP questionnaire and consistency inspection

By inviting customers to fill in AHP questionnaire, conduct pair comparison of importance of cigarette customer needs importance, forming AHP judgment matrix. In this case, seven customers are invited to judge cigarettes customer need importance and calculate consistency ratio of judgment matrix according to formula (1). Judgment matrix and its consistency ratio.

(2) Constitute rough group decision-making matrix, to obtain rough pair comparison matrix

The above five AHP judgments matrix are expressed in the form of rough group decision-making matrix:

$$
P_{1}^{*}=\left[\begin{array}{ccccc}
1,1,1,1,1 & 1 / 5,1 / 4,1 / 2,3,2 & 1 / 9,1 / 4,1,1 / 3,1 / 2 & 1 / 5,1 / 5,1,1 / 2,1 / 2 & 1 / 6,1 / 6,1,2,2 \\
5,4,2,1 / 3,1 / 2, & 1,1,1,1,1 & 2,2,1 / 2,1 / 6,1 / 2 & 1 / 2,1 / 2,1 / 2,1 / 4,1 / 4 & 1,1,1,1,1 / 2 \\
9,4,1,3,2 & 1 / 2,1 / 2,2,6,2 & 1,1,1,1,1 & 1,1 / 2,1,1,1 / 2 & 2,1,2,4,2 \\
5,5,1,2,2 & 2,2,2,4,4 & 1,2,1,1,2 & 1,1,1,1,1 & 2,1 / 3,1,3,3 \\
6,6,1,1 / 2,1 / 2 & 1,1,1,1,2 & 1 / 2,1,1 / 2,1 / 4,1 / 2 & 1 / 2,3,1,1 / 3,1 / 3 & 1,1,1,1,1
\end{array}\right]
$$

According to algorithm, the average rough interval of $p_{12}$ can be obtained:

$$
R N\left(p_{12}^{*}\right)=[0.765,1.992]
$$

Similarly, according to the formula, rough number of all elements and average rough interval of group decision-making matrix can be obtained, and rough pair comparison matrix can be obtainable:

$$
P^{*}=\left[\begin{array}{lllll}
{[1.000,1.000]} & {[0.765,1.992]} & {[0.310,0.664]} & {[0.372,0.772]} & {[0.602,1.519]} \\
{[1.154,3.682]} & {[1.000,1.000]} & {[0.463,1.380]} & {[0.313,0.438]} & {[0.625,0.875]} \\
{[2.160,5.827]} & {[1.528,4.278]} & {[1.000,1.000]} & {[0.625,0.875]} & {[1.611,3.111]} \\
{[1.722,3.722]} & {[2.500,3.500]} & {[1.250,1.750]} & {[1.000,1.000]} & {[1.093,2.426]} \\
{[1.250,4.000]} & {[1.250,1.750]} & {[0.403,0.778]} & {[0.676,2.009]} & {[1.000,1.000]}
\end{array}\right]
$$

(3) Calculate customer needs importance

Cigarettes customer needs importance can be obtainable from the formula (22)

$R N\left(Q^{*}\right)=\{[0.556,1.092],[0.636,1.142],[1.271,2.324],[1.425,2.231],[0.843,1.614]\}$

Cigarette customer needs basic importance is in Table 1 .

Tab. 1 Cigarette customer needs basic importance

$$
\text { Customer needs basic }
$$

Customer needs items

$$
\text { importance } R N\left(d_{i}\right)
$$

Good taste

$[0.556,1.092]$

Strong taste

$[0.636,1.142]$

No throat hurting

$[1.271,2.324]$

Steady quality

$[1.425,2.231]$

Good package

$[0.843,1.614]$

Source: This study.

\section{Cigarette customer needs importance adjustment coefficient based on KANO model}

(1) Customer needs classification based on KANO model

According to the definition of multi-dimensional quality needs based on KANO model and KANO questionnaire template, I designed a KANO questionnaire on cigarette customer needs. 144 consumers filled in the KANO questionnaire, 95 valid questionnaires were recovered. With the classification of customer needs based on percentage, data processing results are shown in Table 2.

Tab. 2 KANO classification on cigarette customer needs

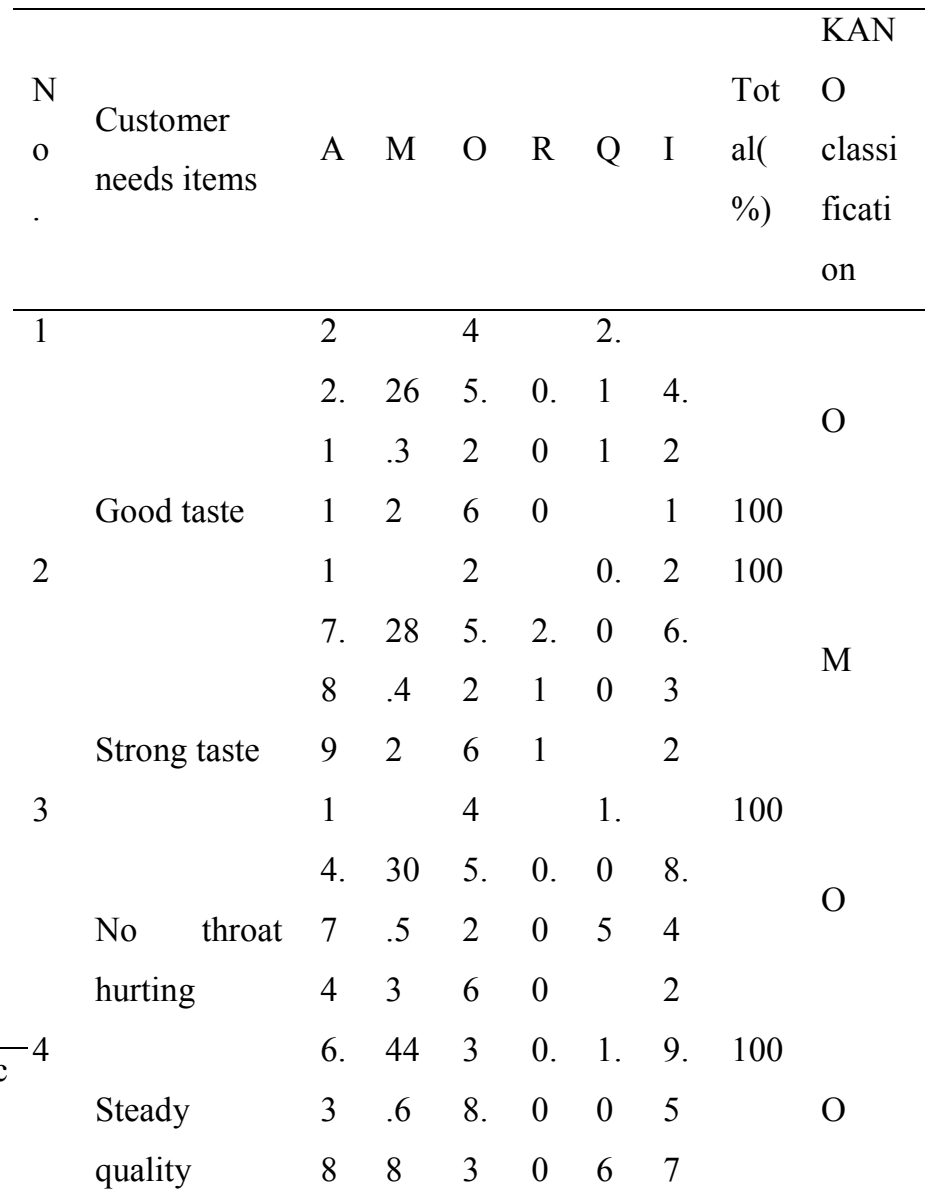


5

$\begin{array}{lllllll}2 & & 2 & & 1 . & 1 & 100 \\ 9 . & 28 & 3 . & 1 . & 0 & 6 . & \end{array}$

Good

$\begin{array}{llllll}1 & .1 & 9 & 0 & 4 & 6\end{array}$

package

$\begin{array}{llll}7 & 3 & 6 & 4\end{array}$

7

Source: This study.

(2) Market competition analysis and customer importance adjustment coefficient based on KANO needs classification

According to conventional steps of market competition analysis, the customers compare and evaluate cigarette products and products of their competitors. Experts group from cross-functional departments of certain company compare and evaluate the result, and set product's target quality value and product characteristics. As shown in Table 3.

Tab. 3 Evaluation table on cigarette market competition

\begin{tabular}{|c|c|c|c|c|c|c|c|c|c|}
\hline o & $\begin{array}{l}\text { Customer } \\
\text { needs }\end{array}$ & 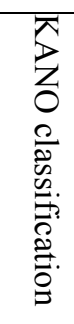 & 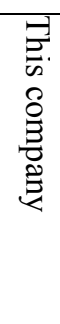 & 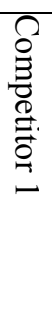 & 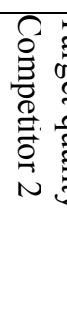 & 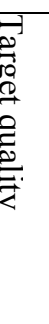 & $\begin{array}{l} \\
0 \\
0 \\
0 \\
0 \\
0 \\
0 \\
0 \\
0 \\
0 \\
0\end{array}$ & & 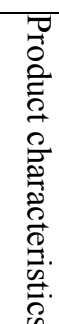 \\
\hline \multirow{3}{*}{1} & Good & & & & & & & & 1. \\
\hline & taste & $\mathrm{O}$ & 4 & 4 & 35 & 52 & 2 & 2 & 2 \\
\hline & & & & & & & 5 & 5 & 0 \\
\hline \multirow[t]{2}{*}{2} & Strong & M & 3 & 3 & 33 & 31 & $\begin{array}{l}1 . \\
0\end{array}$ & $\begin{array}{l}1 . \\
0\end{array}$ & 0 \\
\hline & $\operatorname{tas}$ & & & & & & 0 & 0 & 0 \\
\hline \multirow{3}{*}{3} & No throat & & & & & & 1. & 1. & 1. \\
\hline & hurting & $\mathrm{O}$ & 4 & 4 & 35 & 5 & 2 & 2 & \\
\hline & & & & & & & 5 & 5 & 0 \\
\hline \multirow{3}{*}{4} & Steady & & & & & & 1. & 1 & \\
\hline & quality & $\mathrm{O}$ & 4 & 4 & 45 & 5 & 2 & 2 & 0 \\
\hline & & & & & & & 5 & 5 & 0 \\
\hline \multirow{3}{*}{5} & ood & & & & & & 1. & 1. & 1. \\
\hline & package & A & 4 & 4 & 35 & 5 & 2 & 5 & 2 \\
\hline & & & & & & & 5 & 6 & 0 \\
\hline
\end{tabular}

Source: This study.

(3) Calculation of customer needs importance

According to the calculation result of customer needs basic importance in Table 1, customer needs classification result in Table 2, and market competition evaluation result in Table 3, customer needs importance can be calculated, and the results are in Table 4.

Tab. 4 Customer needs importance calculation

\begin{tabular}{|c|c|c|c|c|}
\hline $\begin{array}{l}\mathrm{N} \\
\mathrm{o}\end{array}$ & $\begin{array}{l}\text { Customer } \\
\text { needs }\end{array}$ & 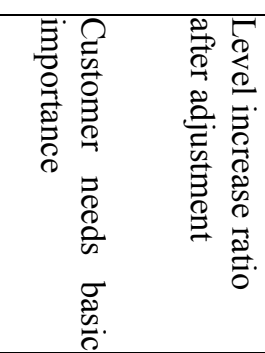 & 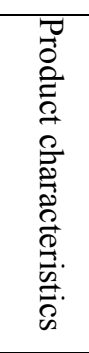 & 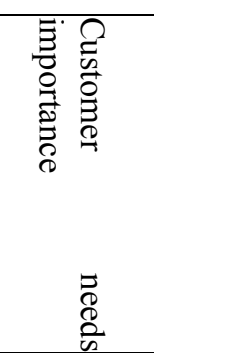 \\
\hline 1 & Good taste & {$[0.556,1.092]$} & 1.20 & {$[0.834,1.638]$} \\
\hline 2 & Strong taste & $[0.636,1.142] 1.06]$ & 1.00 & {$[0.636,1.142]$} \\
\hline 3 & $\begin{array}{l}\text { No throat } \\
\text { hurting }\end{array}$ & {$[1.271,2.324 .2] 5$} & 1.50 & {$[2.384,4.358]$} \\
\hline 4 & $\begin{array}{l}\text { Steady } \\
\text { quality }\end{array}$ & {$[1.425,2.231 .2] 5$} & 1.00 & {$[1.782,2.789]$} \\
\hline 5 & $\begin{array}{l}\text { Good } \\
\text { package }\end{array}$ & {$[0.843,1.614 .56$} & 1.20 & {$[1.578,3.021]$} \\
\hline
\end{tabular}

Source: This study.

According to the calculation results of customer needs importance, comparison drawing of customer needs importance is shown in Figure 2.

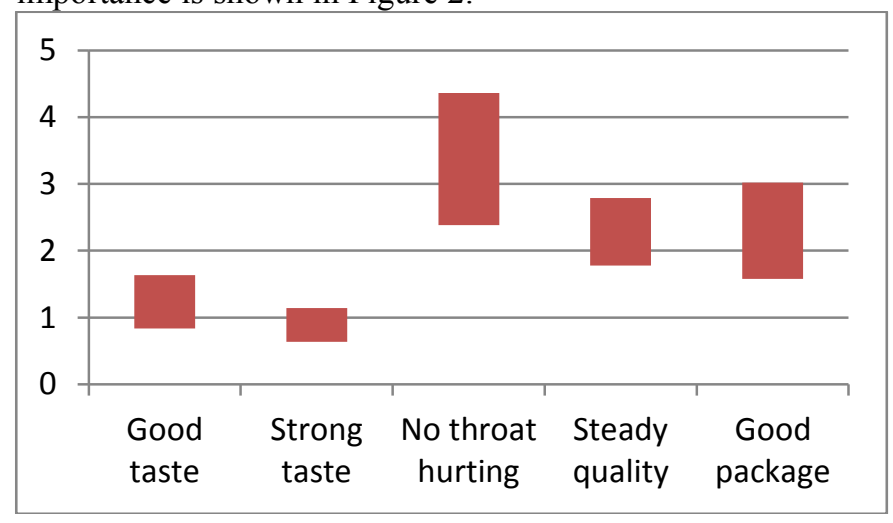

Fig. 2 Cigarettes customer needs importance

According figure 2, the algorithm that this paper proposed calculate the cigarette customer needs importance in rough set. By comparing with traditional customer needs importance research, it could express the ambiguity and uncertainty more validly.

\section{Conclusion}

In this paper, KJ method, rough sets theory, AHP method and KANO theory were integrated to analyze customer needs, constituting customer needs analysis method based on KJ / RAHP / KANO, and put forward customer needs importance 
algorithm based on RAHP and KANO models. This method gave a comprehensive and deep analysis of "voice of the customer" (VOC). KJ method was used to clarify, analyze and reduce customer needs information, obtaining customer needs information in the form of language, which provided a basis for understanding customer needs information. To further tap customer needs information, combination of rough sets, AHP, and KANO methods were used to give a quantitative analysis of relative importance of customer needs and put forward customer needs importance algorithm based on KANO and RAHP models. This algorithm used rough number and rough interval to deal with uncertainty and ambiguity of AHP customer needs importance judgment information. Besides, KANO model was used to conduct rich and detailed explanation to customer needs information, supplementing disadvantage of AHP customer needs importance judgment method caused by difference in the number of customer needs items. Meanwhile, I took cigarettes customer needs as example to explain customer needs analysis process based on QFD / RAHP / KANO and verified the validity of customer needs importance algorithm based on RAHP and KANO models.

\section{Reference}

[1] Cheng, Y.\& Leu, S. Integrating data mining with KJ method to classify bridge construction defects. Expert Systems with Applications, 2011, 38(6): 7143-7150

[2] Cornelis, C., De Cock, M.\& Eikerre, E. Intuitionistic fuzzy rough sets: At the crossroads of imperfect knowledge. Expert Systems, 2003, 20(5): 260-270

[3] Jackson, A. G., Pawlak, Z.\& LeClair, S. R. Rough sets applied to the discovery of materials knowledge. Journal of Alloys and Compounds, 1998, 279(1): 14-21

[4] Jain, V. K.\& Sobek II, D. K. Linking design process to customer satisfaction through virtual design of experiments. Research in Engineering Design, 2006, 17(2): 59-71

[14]
[5] Kano, N. Life cycle and creation of attractive quality. Linkoping, Sweden, 2001

[6] Kano, N., Seraku, N.\& Takahashi, F. Attractive quality and must-be quality. Journal of the Japanese Society for Quality Control, 1984, 14(2): 39-48

[7] Kwong, C. K.\& Bai, H. Determining the Importance Weights for the Customer Requirements in QFD Using a Fuzzy AHP with an Extent Analysis Approach. IIE Transactions, 2003, 35(7): 619-626

[8] Nepal, B., Yadav, O. P.\& Murat, A. A fuzzy-AHP approach to prioritization of CS attributes in target planning for automotive product development. Expert Systems with Applications, 2010, 37(10): 6775-6786

[9] Pawlak, Z.\& Skowron, A. Rough sets: Some extensions. Information Sciences, 2007, 177(1): 28-40

[10] Saaty, T. L. The analytic hierarchy process: Planning, priority setting and resource allocation. New York: McGraw-Hill, 1980: 196-203

[11] Tan, K. C., Shen, X. X. Integrating Kano's model in the planning matrix of quality function deployment. Total Quality Management, 2000, 11(8): 1141-1151

[12] Tan, K. C., Xie, M.\& Shen, X. X. Development of innovative products using Kano's model quality function deployment. International Journal of Innovation Management, 1999, 3(3): 271-286

[13] Wang, X. T. Research on quality function deployment under uncertain circumstances. Doctoral Dissertation of Zhejiang University, 2011. 